\title{
Os Primórdios da Doutrina de Segurança Nacional: A Escola Superior de Guerra ${ }^{1}$
}

\author{
The Origins of National Security Doctrine: The War College
}

Nilo Dias de OLIVEIRA ${ }^{\bullet}$

\begin{abstract}
Resumo: O presente artigo tem como objetivo analisar a Escola Superior de Guerra (ESG), na visão de seus integrantes na formulação de uma doutrina de segurança nacional na década de cinquenta, através dos relatórios do Serviço Secreto da Delegacia de Ordem Política e Social de São Paulo DOPS-SP e no arquivo pessoal do General Juarez Távora do acervo documental do CPDOC-FGV. A dimensão dessa doutrina não se tratava apenas de uma mera participação no intenso embate político nacional que ocorria na sociedade civil e nas Forças Armadas naquela conjuntura, mas sim um projeto de hegemonia que se transformaria em um arcabouço teórico eficaz na consolidação da autocracia burguesa bonapartista pós 64. Dentro dessa visão, somente os militares seriam capazes de alterar o caráter, a cultura e a índole do povo brasileiro.
\end{abstract}

Palavras-chave: ESG; Lei de Segurança Nacional; Autocracia burguesa.

Abstract: This article aims to analyze the National War College (Escola Superior de Guerra (ESG)) in view of its components in the formulation of a national security doctrine in the 50s, through the reports of the Secret Service of the Bureau of Political and Social Order of São Paulo - DOPS-SP and the personal archive of General Juarez Távora from documentary collection of CPDOC-FGV. The size of this doctrine was not just the mere participation in the intense national political struggle which was in the civil society and the the Armed Forces in that context, but a project of hegemony which will become effective at a theoretical consolidation of the Bonapartist bourgeois autocracy after 64 . Within this vision, only the military would be able to alter the character, culture and temperament of the Brazilian people.

Keywords: ESG; National Security Law; Bourgeois Autocracy.

\section{Escola Superior de Guerra: “o mundo é das elites."}

Segundo José Murilo de Carvalho, desde a década de trinta era possível detectar nas Forças Armadas brasileiras três modelos de conflito ideológico e político; o primeiro refletia a influência do profissionalismo alemão e francês advindo entre 1906 e 1912 através dos jovens oficiais que estagiaram respectivamente na Alemanha e na França. Esses seguiam o modelo das democracias liberais, onde o exército podia e devia dedicar-se primordialmente à defesa externa. Eram contrários à interferência do exército nos assuntos políticos nacionais.

O segundo, chamado de intervencionismo reformista, era defendido por um oficialato que não se ligava às classes dominantes e considerava que havia momentos em que a instabilidade política permitia e quase exigia a intervenção dos militares na política interna (essa concepção surgiu com os positivistas no fim do século XIX e ampliou-se com o tenentismo na década de 20). Esse grupo propunha um extenso programa de reformas econômicas, políticas e sociais, além de defenderem

\footnotetext{
- Mestre em História - Doutorando - Faculdade de Ciências Sociais - PUC-SP - Pontifícia Universidade Católica de São Paulo - Campus de Perdizes - Rua Monte Alegre, 984, CEP: 05014-901, São Paulo, SP, Brasil. Pesquisador do CEHAL - Centro de Estudos de História Latino Americana e do NEHTIP - Núcleo de Estudos de História: Trabalho, Ideologia e Poder da PUC-SP. E-mail: nilodiasoliveira@gmail.com
} 
um papel de liderança para a elite militar considerada a mais bem organizada, a mais autorizada, a mais capaz. ${ }^{2} \mathrm{O}$ terceiro era a dos militares mais radicais, tanto praças como oficiais. Em sua forma extremada refletia a influência do PCB, cujo prestígio entre as Forças Armadas crescera muito após este partido ter conseguido a adesão do ex-capitão Luís Carlos Prestes em 1931. Esse quadro defendia a ideia de um exército popular que deveria ser um instrumento da luta de classes.

Apesar destas divergências, os militares garantem a sustentação da ditadura de cunho bonapartista $^{3}$ de Getúlio. No entanto, nos anos seguintes, já no início da $2^{\text {a }}$ Guerra Mundial, uma parte da oficialidade revelava uma postura militar intervencionista no controle do Estado a favor do desenvolvimento e da segurança nacional. Como no golpe de 1945,

as grandes mobilizações de massas promovidas no bojo do queremismo, os discursos populistas do Presidente Vargas, o exemplo do peronismo, constituíam uma ameaça mais concreta à ordem social e política do que a percebida em 1937. (CARVALHO, 2005, p.100).

Nos anos seguintes, com a crise do governo de Getúlio, em 1945, até o golpe de 1964, ocorre a fragilização da fração das Forças Armadas que davam sustentação à ditadura, conforme afirma ainda José Murilo de Carvalho,

A organização militar que se alterava profundamente na estrutura, na ideologia e no poder político por força do próprio acordo com Vargas, mostrou-se incompatível com a reorientação ideológica e política do presidente. Incompatível, sobretudo, com a tentativa de mobilizar novo ator político, o operariado. A partir daí, a luta foi sem trégua. A morte de Vargas em 1954 não pôs fim ao conflito, pois se passou então a combater sua herança política, ou seu fantasma que se diziam encarnados em Juscelino Kubitscheck e João Goulart. Em 1964, travou-se a batalha final que deu a vitória à facção militar anti Vargas e a seus aliados civis, abrindo-se novo ciclo político na história do país. (CARVALHO, 2005, p.102).

Nessa perspectiva, a reordenação das forças políticas em torno do governo Vargas não só afastava os militares das posturas do presidente, mas também a burguesia industrial, a qual via na aproximação do governo com a classe trabalhadora, além do perigo de instabilidade social, o ônus que o empresariado teria que arcar com a tolerância sindical.

De qualquer forma, segundo os militares, o avanço comunista era iminente, o que exigia sua presença constante no cenário político, reforçada pela percepção da sociedade civil, que de fato, as Forças Armadas eram os únicos defensores da ordem e da segurança nacional.

Neste sentido, a criação da Escola Superior de Guerra (ESG) em 1948, coaduna estas duas circunstâncias que, conforme Oliveira, se caracterizou como um

instrumento de relação orgânica entre setores militares e grupos das classes dominantes, entre grupos militares e outros setores do aparelho de Estado (magistrados, políticos, educadores, embaixadores - numa dimensão política e burocrático-administrativa), com o objetivo de promover determinado tipo de desenvolvimento econômico (de tipo capitalista), dirigido por um grupo específico 
(as elites) e dotado de uma ideologia (a ideologia da SN) e uma opção estratégica (o Mundo Ocidental), sob a hegemonia dos Estados Unidos. (OLIVEIRA, apud ASSUNÇÃO, 1999, p.38).

A ESG tornou-se uma instituição que mesclou as orientações americana, francesa e alemã no desenvolvimento do quadro conceitual a seu próprio respeito e sobre a sua função na sociedade ${ }^{4}$. Ela seguiu a tendência internacional no período da Guerra Fria que levou a Inglaterra, França e Estados Unidos ${ }^{5}$ a criarem estabelecimentos destinados ao preparo de suas nações para uma política de guerra integrada contra o comunismo liderado pela Rússia.

Segundo o General Antônio Jorge Corrêa ${ }^{6}$, um dos integrantes da ESG desde seus primórdios, explica anos mais tarde, as razões da criação desta instituição, e seu discurso esclarece a função social que se atribuem às Forças Armadas no país. Segundo ele:

A consciência de que era mister criar uma elite preparada para a missão de interpretar as legítimas aspirações e autênticos interesses nacionais, de formular através de um método científico a política e estratégia nacionais, com um critério que transbordasse dos limites da defesa nacional, cujo sentido era restritivo, levou o nosso Governo a pensar, inicialmente, na criação de um curso de altos estudos, frequentado apenas por oficiais da Marinha, Exército e Aeronáutica (decreto de outubro de 1948 do Governo do Presidente Dutra) Tal critério logo evoluiu para o da criação de "um instituto de altos estudos, voltado para o planejamento e a direção da segurança nacional" (lei de 20 de agosto de 1949). (CORRÊA Apud SILVA, 1976, p.465).

Segundo Francisco Ferraz há dois documentos básicos para entender a Escola superior de Guerra, um do general Osvaldo Cordeiro de Farias intitulado "Razões que levaram o governo a pensar na organização da Escola Superior de Guerra" e o outro do tenente-coronel Idálio Sardenberg, intitulado "Princípios fundamentais da Escola Superior de Guerra". Ambos foram transcritos na Revista da Escola Superior de Guerra. Utilizaremos essa documentação para demonstrar a preocupação das Forças Armadas em conduzir o processo político "pelo alto", endossando a crença de que as elites são responsáveis pelos destinos da nação.

A movimentação popular através dos sindicatos, das associações democráticas em defesa de uma maior participação política e econômica dos vários segmentos excluídos iria endossar cada vez mais aquela tese, reforçando tanto a necessidade da intervenção militar nos destinos da nação, como a formulação de uma doutrina de Estado militar. Dentro desta visão, somente os militares seriam capazes de alterar o caráter, a cultura e a índole do povo brasileiro. Compunham, conforme afirmava o General Juarez Távora, a elite nacional capaz de garantir a consolidação da nação:

Objetivos nacionais são realidades ou aspirações relacionados com a integração física, política, econômica ou social de uma nação, e que, consubstanciados no espírito da elite, se transmitem à sensibilidade do povo-massa com hábitos ou necessidades unânimes ou generalizadas da coletividade nacional. ${ }^{7}$ 
Observa-se nos discursos de alguns dos generais esguianos que estes não viam as Forças Armadas atuando de forma autônoma ou assumindo o controle total das decisões sobre o desenvolvimento nacional. Pelo contrário, uma organização adequada do governo, conforme afirmava o General Cordeiro de Farias fortaleceria as classes armadas:

a segurança nacional repousa, antes de tudo, em uma organização adequada de governo, em que o planejamento seja a preocupação maior. Desse planejamento geral surgirá um incremento da economia, tomada ela no sentido mais amplo e de onde emergirá, final e naturalmente, uma organização sólida para as classes armadas. $^{8}$

A opinião pública seria fundamental para o endosso das medidas tomadas pelo executivo, no caso as Forças Armadas. O consenso era o motor primordial para a repressão, na medida em que essas ações reacionárias iriam ferir a Constituição e o Estado de Direito,

Consequência deste fato é a necessidade de um esclarecimento continuado, permanente da opinião pública que deve ser alertada para a hora difícil em que vive o mundo [...] Esta obra deverá ser das elites esclarecidas e, antes de tudo, das que tem por missão plasmar o caráter e formar a cultura da nossa mocidade, [...] todos instrumentos que tanta e tamanha força representam nos dias que ocorrem. (FARIAS apud FERRAZ,1994, p.26).

Conforme indicam os analistas, tais ideias não são exclusivas das casernas, expressando, antes de tudo, um arcabouço conceitual vigente desde as primeiras décadas do século XX desenvolvido no interior dos segmentos dominantes. Segundo Lamounier,

caracterizavam-se por uma visão orgânico-corporativa da sociedade, sendo os conflitos sociais administrados pelo Estado, o que deslegitimaria a organização autônoma da sociedade civil, tornando desnecessária sua organização em partidos e ou associações. Mas o mais notável, porém, é que nestas ideologias que povoaram as mentes dos ideólogos dos anos 20 e 30, transitava-se facilmente de um elitismo altruísta para o voluntarismo golpista, tornando legítima, para as elites, o emprego temporário da força, sendo a corporação armada geralmente a fiel da balança, seja como parceira, seja como adversária. (LAMOUNIER, apud FERRAZ,1994, p.35).

Esse pendular do elitismo altruísta para o voluntarismo golpista que, conforme os autores acima legitimavam para as elites, o emprego temporário da força, ou seja, a corporação armada, também é reconhecida por Chasin, mas em posição antagônica, pois, conforme este, analisar a dinâmica histórica restringindo-se à análise da ideologia, acaba por reproduzir a conduta politicista que os segmentos da burguesia têm, pois

Politicizar é tomar e compreender a totalidade do real exclusivamente pela sua dimensão política e, ao limite mais pobre, apenas de seu lado político-institucional. Enquanto falsificação teórica e prática, o politicismo é um fenômeno simétrico ao economicismo. [...] O politicismo arma uma política avessa, ou incapaz de levar em consideração os imperativos sociais e as determinantes econômicas. Expulsa a economia da política [...] jamais admitindo o caráter ontologicamente fundante e matrizador do econômico em relação ao político. (CHASIN, 2000, p. 123-124). 
Ao analisar o movimento fundante da particular dinâmica histórica do Brasil, este autor demonstra como a instauração do capitalismo neste país configura uma dada burguesia que era frágil enquanto classe, débil nos liames do capitalismo e incapaz de cumprir a função social de promover a revolução que, rompendo com os segmentos conservadores, dê concretude plena às forças produtivas liberadas pela industrialização, mesmo que de forma hiper tardia. Conforme o autor,

a particularidade da via colonial [...] engendra uma burguesia que não é capaz de perspectivar, efetivamente, sua autonomia econômica, ou o faz de um modo demasiado débil, conformando-se, assim, em permanecer nas condições de independência neo-colonial ou de subordinação estrutural ao imperialismo. /.../ De modo que, se para a perspectiva de ambas [as burguesias que se objetivaram pela via colonial e prussiana], de fato, é completamente estranha a efetivação de um regime político democrático-liberal, /.../ a burguesia produzida pela via colonial tende a não romper sua subordinação, permanecendo atrelada aos pólos hegemônicos das economias centrais. (CHASIN, 2000, p. 128-129).

Tal subordinação manifesta-se também, na sua incapacidade de romper com os segmentos da burguesia agrária com os quais disputa a hegemonia do poder político e na impossibilidade de fortalecer-se via articulação com outros segmentos sociais subalternos, tais como os trabalhadores. Comprimida entre as demandas de modernização exigidas pelo desenvolvimento do capital internacional e ante a reação social inerente às contradições de classes vigentes nestas formações, seus projetos de desenvolvimento transitam entre a "forma da autocracia burguesa bonapartista para

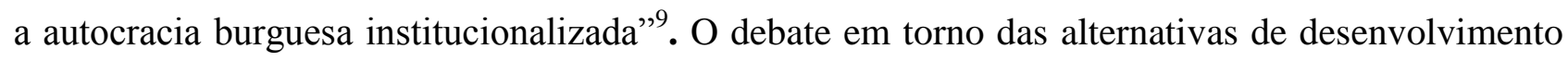
entre os segmentos da burguesia e no interior do alto oficialato que compunha a ESG e que se reunia no Clube Militar com seus pares demonstra bem esta condição.

Por um lado, indica que na forma estatal em que se manifesta a autocracia burguesa institucionalizada, segmentos sociais que no período ditatorial não tinham espaço para fazer valer seus interesses, agora o têm, embora ainda de forma restrita. Por outro, indica o receio que todos têm da abertura institucional, pois esta põe em risco a ordem vigente. Ainda mais quando as propostas começam a esboçar formas alternativas ao modelo de capitalismo em curso e que garante as benesses ao segmento da burguesia atrelado ao capital internacional, para prejuízo, inclusive de outros segmentos da burguesia que não conseguem o mesmo espaço e benefícios.

Tal articulação toma, assim, a forma, e apenas a forma, de um debate de natureza antagônica entre internacionalistas e nacionalistas. Reforçando essa tese, a crítica do historiador Rago sobre o mito da burguesia nacionalista:

Desmanchava-se, assim, todas ilusões de uma burguesia nacionalista que tendo em mira a sua emancipação particular, se colocava como a representante dos interesses gerais, aqui, ao contrário, apoiando-se em formas autocráticas, atuou mais como uma burguesia com interesses cada vez mais mesquinhos e particularistas, 
acelerando o processo de concentração e centralização do capital, por meio da superexploração da força de trabalho e com a exclusão das maiorias do próprio mercado interno. (RAGO,1998, p.324).

Assim, ante a impossibilidade da construção de um Estado com participação das classes subalternas, os primórdios da industrialização capitalista no Brasil e seu posterior desenvolvimento terão na violência a única forma de garantir o Estado atrófico que se desenvolvia no Brasil naquela conjuntura, conforme afirma Lívia Cotrim:

A industrialização subordinada ao capital externo, capitaneada pela produção de bens de consumo duráveis, conciliada com a estrutura agrária herdada da colônia e assentada na superexploração do trabalho, portanto na exclusão econômica dos trabalhadores, é a marca da estreiteza política: incapaz de dominar sob forma efetivamente democrática - porque impossibilitada de lutar ou sequer perspectivar sua autonomia econômica, e, assim, de se pôr à frente de um projeto de cunho nacional, apto a incluir, embora nos limites do capitalismo, as classes a ela subordinadas -, a burguesia brasileira só pode exercer seu poder político sob forma autocrática. (COTRIM.2000, p.VI).

Nessa perspectiva, o final da Guerra Fria somente intensificou essa prática inerente ao capitalismo brasileiro, na medida em que o crescimento das agremiações de esquerda e a mobilização da classe trabalhadora representavam um perigo iminente para os interesses da burguesia engendrada nos interesses do capital mundializado. Assim, o estabelecimento da ESG naquele período e o debate sobre os riscos da democracia que aí se configura caracterizam a ação das Forças Armadas em prol a manutenção do "status quo", seja defendendo um desenvolvimento com maior ou menor participação do capital internacional. É neste contexto que se gesta o ideário sobre a segurança nacional que, posteriormente, engendra a Doutrina de Segurança Nacional ${ }^{10}$. Neste sentido, retomando Francisco Ferraz:

Esta confluência de aspirações entre elites militares e civis pôde fazer da recémimplantada Escola Superior de Guerra um espaço privilegiado para a moldagem de um projeto político comum. Estavam, assim, cada vez mais distantes as reservas existentes entre os membros das Forças Armadas e algumas frações burguesas em ascensão, o que acabaria permitindo um relacionamento mais equilibrado. A doutrina da Segurança Nacional, ideologia aglutinadora desses interesses, contribuía para a ação política de classe, gestando estrategicamente um planejamento com fins específicos, voltado para a construção de uma sociedade industrial plenamente articulada ao capitalismo mundial. (FERRAZ, 1994, p.44).

\section{Sorbonistas e nacionalistas: A linha tênue do nacionalismo e o internacionalismo.}

Autores que vêm se dedicando ao estudo das Forças Armadas no Brasil contemporâneo já consideram as evidências de seu alinhamento com os ditames dos Estados Unidos para a América Latina e o Caribe, particularmente após a segunda guerra mundial. ${ }^{11}$ Tais autores enfatizam também a estreita vinculação deste alinhamento com os segmentos das burguesias nacionais 
atreladas aos interesses das multinacionais. Assim por exemplo, conforme Dreifuss, a ESG se pautava por uma

Ideologia que defendia um alinhamento político e ideológico com os Estados Unidos. Incentivava, dentro das próprias Forças Armadas, um desenvolvimento que deveria ser norteado por valores empresariais e multinacionais e que resultaria em um Estado que manteria a estabilidade através do autoritarismo político da doutrina de segurança nacional, e de um governo forte e centralizador. (DREIFUSS, 1981, p.79).

Tal doutrina é tanto mais acentuada em seus aspectos coercitivos e persecutórios quanto o é a dependência e a subordinação de cada um destes países aos centros de desenvolvimento do capitalismo. A retomada da capacidade produtiva europeia e norte-americana será relativamente contrária à crise que se abate no continente latino americano. A esses países se acrescem as políticas de retomada do crescimento com crescente endividamento, inflação, aumento da concentração de renda e da exclusão social - que se manifesta com a formação de cordões de marginalidades nas zonas urbanas das principais cidades do continente.

Tal condição deu ensejo, por um lado, ao fortalecimento de ideias que buscavam alternativas de solução para esta situação, encontrando, as organizações ditas de esquerda, um campo fértil para o debate e seu fortalecimento, de que foram auxiliadas pela condição "democrática" que vicejava. Neste contexto, os debates sobre as alternativas ao desenvolvimento ampliam-se nos diferentes grupos que compunham a sociedade.

Por outro lado, tais condições fazem crescer o receio da burguesia dominante, ampliado pelo medo de uma "cubanização" do continente levando-os a posturas mais reacionárias e à elaboração de alternativas de contenção social a serem viabilizadas a nível nacional. Tal receituário encontra nas discussões promovidas pelos intelectuais da ESG o espaço adequado para sua formulação. Conforme aponta a socióloga Maria Helena Moreira Alves:

O desenvolvimento de teorias da guerra fria resultou em ênfase para interpenetração de fatores políticos, econômicos, filosóficos e militares na formulação da política de segurança nacional, passando-se a dar crescente prioridade ao adestramento em teoria do desenvolvimento. Pelo alto nível de seu ensino, a ESG tornou-se conhecida como a "Sorbonne" do establishment militar. (ALVES, 2005, p.28).

A ESG valia-se também de outras ideologias conservadoras presentes na sociedade brasileira e nas Forças Armadas como a visão republicana positivista ${ }^{12}$. Dentro desse universo "ideológico brasileiro" o início do século XX é marcante para o desenvolvimento do pensamento autoritário, conforme bem observa a socióloga Lívia Cotrim:

O caráter autoritário do ideário getuliano não seria um caso excepcional; ao contrário, existiriam traços comuns entre seu pensamento e o de diversos outros ideólogos brasileiros, como Plínio Salgado, Azevedo Amaral, Francisco Campos e 
Oliveira Vianna, quais sejam: afirmação de um hiato entre o Brasil "real" e o "legal", oposição ao liberalismo e às oligarquias, isto é, ao status quo; defesa, contra o poder oligárquico, do fortalecimento do estado nacional e da supremacia do executivo; a necessidade de substituir as decisões de cunho político por soluções técnicas, para as quais o executivo federal deveria se apoiar em órgãos técnicos; defesa da perspectiva nacionalista, entendida não como restrição à entrada de capital externo, mas sim como a necessidade de não copiar modelos de outros países; crença na existência de um "destino histórico" do Brasil, para cujo alcance seria necessário o intervencionismo centralizador e modernizante, para incentivar a industrialização. De sorte que o pensamento autoritário convergiria com os interesses da burguesia industrial, isto é, com a constituição da nova ordem capitalista. (COTRIM. 1999, p.37).

Assim é que, quando da fundação da Escola, observava-se um crescente processo de mobilização de amplos segmentos da sociedade e um conflito latente entre posições nacionalistas e internacionalistas que expressam o desenrolar dos acontecimentos nos anos anteriores, encetados no período Vargas.

Ao término do segundo governo de Getúlio Vargas (1951-1954), o Brasil se apresentava como um país que havia passado por uma série de mudanças estruturais que haviam ganhado velocidade a partir da década de 1930, sob a égide do bonapartismo getulista que transita, conforme dissemos, para a institucionalidade autocrática. Essas mudanças diziam respeito principalmente às bases do desenvolvimento, ao modelo econômico adotado, à ênfase na industrialização orientada pelo Estado, à liberalização política e ao controle social e sindical.

Nesse contexto de desenvolvimento o projeto de cunho mais nacionalista, inspirado em alguns dos princípios da Comissão Econômica para a América Latina $(\text { Cepal })^{13}$, rejeitava a abertura da economia ao capital estrangeiro sem limites, considerando que era necessário sujeitar estas parcerias a algumas limitações. Consideravam, seus defensores, que jamais um país do centro da economia mundial capitalista aceitaria transferir recursos para um país periférico, como o Brasil, a ponto de transformá-lo em um concorrente. Consideravam que, do ponto de vista do capital internacional, era necessário estabelecer sérias restrições aos investimentos. Além disso, o endividamento externo era desaconselhável, e acreditar que as multinacionais transfeririam tecnologia de ponta para o país se manifestava uma tremenda ingenuidade.

Tal perspectiva nacionalista corroborava com os preceitos das organizações de esquerda que entendiam ser o momento propício para o combate histórico entre a nação (representada pela "burguesia nacional progressista" e as "massas conscientes") e a antinação (representada pelos setores "atrasados" da classe dominante, pelas "massas alienadas" e pelo capital estrangeiro ou as “forças do imperialismo". Acreditavam que, através de uma aliança estratégica com a burguesia industrial, haveria conquistas significativas para a classe operária e a sociedade civil.

Por outro lado havia também um projeto liberal ou internacionalista, cujos formuladores acreditavam que países como o Brasil, de recente desenvolvimento industrial e com escassas 
reservas de capital, não teriam condições de promover o desenvolvimento por conta própria, sendo necessário recorrer ao capital internacional. Como este estava disponível em grande volume, sobretudo nos Estados Unidos, garantir-se-ia um desenvolvimento acelerado. A penetração do capital estrangeiro seria feita por empréstimos ou aplicação direta de empresas multinacionais, com a correspondente transferência de tecnologia. $\mathrm{O}$ aumento da dívida externa era considerado um problema secundário, uma vez que a manutenção de elevados índices de crescimento econômico acabaria por torná-la insignificante.

Tal debate, que ocorria no interior destes segmentos da sociedade civil, praticamente se reproduzia no interior das Forças Armadas, principalmente no exército. De um lado se punham os intelectuais da ESG denominados de "sorbonistas", cujo posicionamento político os aproximava do projeto liberal ou internacionalista, e de outro os nacionalistas, os quais formavam a facção do exército simpatizante com as ideias getulistas, contrários à intervenção militar na política (a não ser para garantir o estado de direito na defesa da Constituição ${ }^{14}$ ) e que consideravam necessário garantir o desenvolvimento da nação um pouco mais distante do poderio do capital internacional.

Cabe ressaltar a dificuldade de estabelecer "rótulos" para essas facções militares, como observa Lúcio Flavio de Almeida,

ao longo do processo, os próprios atores sofreram profundas alterações e, com eles, as configurações concretas adquiridas pelo nacionalismo e pelo antinacionalismo [...] as forças anti-industrialistas possuíam um peso político ideológico significativo até o início do período JK. Muitos de seus membros, sempre esgrimindo um discurso crítico em relação ao nacionalismo, transitariam de uma posição antiindustrialista para uma clara defesa do grande capital monopolista dependente no contexto de um capitalismo industrial que, ao longo da segunda metade dos anos 1950, sofreria cada vez menos questionamentos de caráter agrarista. Este deslizamento, bem como a escassa margem de manobra mencionada acima, foi importante para explicar o fraco teor nacionalista das posições concretamente adotadas pela Escola Superior de guerra ao longo dos anos 1950 (e inicio dos 60), bem como, inclusive, a adoção de posições antinacionalistas por militares vinculados a esta instituição. (ALMEIDA, 2006, p.82).

O paradoxo se evidencia: quanto mais o discurso nacionalista se aproximava do das classes subalternas e perspectivava reformas sociais (melhores condições de trabalho, diminuição de jornada, aumento salarial, o direito a greve, reforma agrária, participação política) que poderiam aproximar o país de uma democracia de cunho liberal burguês; mais as classes dominantes não os reconheciam como forças políticas legítimas, cabendo ao Estado criminalizar de toda a sorte os movimentos sociais progressistas. ${ }^{15}$

É nessa perspectiva que os integrantes da ESG se colocam como os "verdadeiros nacionalistas", em detrimento dos "nacionalistas comunistas", liderados pelo PCB, que segundo os "sorbonistas", estavam infiltrados nas Forças Armadas pelos militares getulistas, nos sindicatos, nas associações partidárias. Afinal, é através da criminalização dos movimentos reivindicatórios e da 
banalização das necessidades das classes subalternas traduzidas como "plataformas de cunho comunista", que o ideário autocrático se dinamiza no conceito de que a nação decorre da organização e consolidação de uma doutrina da sociedade civil. Assim, cabe a cada membro o seu devido papel, reforçando a falácia que através de um pacto social entre trabalhadores e a burguesia industrial/agrária, se alcançaria a "paz social".

Diante disso, a sociedade civil outorgaria às Forças Armadas o papel de dirigentes e restauradores dos "valores nacionais", propiciando assim o desenvolvimento econômico e social do país traduzidos no binômio: segurança e desenvolvimento. Conforme observa a socióloga,

às elites cabe um poder hegemônico de interpretação dos objetivos nacionais. Ao mesmo tempo, as elites devem incutir no povo, objetivos por ela definidos, a fim de garantir o aperfeiçoamento material ou espiritual da nação. (ASSUNÇÃO, 1999, p.48).

No interior da ESG os "sorbonistas" acreditavam que as razões do nosso subdesenvolvimento eram intrínsecas às características do povo brasileiro, cujas massas eram despreparadas, subdesenvolvidas, analfabetas e sem condições de manifestação próprias em defesa de seus interesses. Em conformidade com o que pregavam os segmentos dominantes da burguesia, consideravam que caberia à elite nacional imbuí-las de valores nacionais e projetar o caminho a ser seguido pela nação, ou seja, na condição de massas às quais caberia, conforme denuncia o historiador Rago,

um papel intrinsecamente menor e subordinado, são sempre manipulados e orientados para o bem ou para o mal, nas escolhas políticas articuladas pelas "elites dirigentes". [...] as massas populares [...] somente poderiam vir a ser instrumentalizadas, seja ao "comunismo", seja ao "populismo", pelos líderes e tendências ideológicas, com seus projetos políticos "próprios", sempre em oposição à índole nacional. (RAGO, 1998, p.69).

A estas noções de elite e massa, agregam estes intelectuais da caserna os conceitos geneticistas apregoados pelos ideólogos conservadores da década de 20 e 30, isto é, que o fracasso político do país era devido à "mulatização" e "sifilização" do povo brasileiro que, como herança genética, impregnava o país de um derrotismo estrutural. Conforme o General Góes Monteiro, líder da Revolução de 1930 e integrante da ESG, em entrevista no jornal Diário da Noite, em 31/03/1951 anexado no relatório da DOPS:

O Brasil é de uma infelicidade no terreno político, que não conserta mais" Declarou o general Góes Monteiro, quando interpelado pelo repórter, relembrando entrementes a nossa mulatização a par da "sifilitização" atávica, que nos marca tremendamente. E prosseguiu: - Não podemos esperar nem uma grande revolução saneadora nem da evolução natural, modificações salutares para o nosso grande país, tantas vezes denominado com frequência, "país do futuro". Refletindo um pouco sobre suas palavras, o chefe da revolução de 30, que já avisara ao repórter 
não ter mais peias políticas que lhe travassem a língua, raciocinou: - O território é muito grande e talvez o homem seja pequenino demais. ${ }^{16}$

Nesse mesmo diapasão é a fala de um coronel sobre as qualidades do seu candidato, o general Etchegoyen apoiado pela Cruzada Democrática composta pelos militares da ESG no pleito do Clube Militar ${ }^{17}$ em 22/05/1952, quando concorriam às eleições, de um lado, o Genereal Estilac Leal apoiado pelos nacionalistas e de outro o referido general,

era um homem capaz de limpar o Clube Militar, eliminando sumariamente muitos sargentos, negros retintos e mulatos pernósticos, que passaram para a reserva no posto de tenente, sendo admitidos como sócios pelo general Estilac e seus adeptos, o que não só contrariou grande número de sócios do Clube Militar, como também afastou das reuniões dançantes e festas sociais, famílias das mais distintas e frequentadores tradicionais do Clube Militar. ${ }^{18}$

Outro aspecto intrigante na fala destes generais além do preconceito racial e de classe é culpabilizar o povo pelas mazelas nacionais, apontando a corrupção como um traço cultural do povo brasileiro, o que tornava a sociedade como um todo incapaz de se organizar. Esta manifestação de um viés politicista na interpretação deste General aparece claramente na sequência do discurso do general Góes Monteiro no referido jornal, cuja lógica é, no mínimo, intrigante.

O nosso regime é um misto de democrático, autocrático e cleptocrático, uma combinação espúria e retrógrada, que serve para um pequeno número de privilegiados e que faz a ruína e aumenta a miséria da grande massa popular, quase sem resistência. ${ }^{19}$

A percepção que passam a desenvolver sobre sua missão social os faz ter a ilusão de que estão acima das contradições de classe e acima das manifestações da autocracia burguesa. Tal perspectiva permite a este General, um dos expoentes do pensamento ESGuiano no período, considerar que a falência dos poderes constituídos se manifestava na evidência de que o poder do Estado, por estar nas mãos dos civis, corrompia a coisa pública e subordinava os interesses da nação aos interesses de classe "que serve(m) para um pequeno número de privilegiados e que faz(em) a ruína e aumenta(m) a miséria da grande massa popular, quase sem resistência" 20 .

Cabe aqui um adendo quanto a este documento, que diz respeito diretamente ao objeto de estudos no qual a minha dissertação de mestrado abordou, ou seja, a extensão da vigilância entranhada no Estado brasileiro.

O autor deste documento é um censor que pertence ao Serviço Secreto, infiltrado no Clube Militar para acompanhar este pleito e que, em seu relatório indicado como "reservado" relata, como vimos acima, as impressões dos seus componentes. Portanto, tal censor pertencia ao Clube Militar e uma de suas funções secretas era vigiar seus próprios companheiros, ou seja, pode-se considerar que muitos se vigiavam mutuamente e os relatos sobre suas convicções transparecem na documentação 
produzida por eles mesmos na qualidade de censores secretos. Toda a documentação utilizada para a caracterização deste ideário da ESG na década de 50 são relatórios do mesmo teor e autorias.

Este documento, por conseguinte, nos revela dois aspetos profundamente arraigados no cenário nacional: o enraizamento dos serviços de vigilância que mapeavam opiniões, expressões, tendências políticas e posicionamentos pessoais, inclusive no interior do aparato militar e a sua visão excludente das classes subalternas que subjaz no ideário da segurança nacional.

Nessa mesma linha de raciocínio, em outro documento produzido da mesma forma, o general Inácio José Veríssimo, numa reunião de oficiais superiores na capital do Pará em 28/04/1954, criticou a lei eleitoral chamando-a de obsoleta, arcaica e improfícua, "pois o voto de uma lavadeira tem o mesmo valor de um general”, "e os problemas do país são devido à sua população ser semianalfabeta", propondo que o voto fosse qualificado. ${ }^{21}$ Além de ficar evidente a visão excludente do oficial das classes subalternas em relação ao direito ao sufrágio, chama atenção também à ação violenta da polícia após passeata dos estudantes repudiando tal declaração.

Conforme se observa, apesar dessa visão da supremacia das elites na condução do processo político e econômico do Brasil, as Forças Armadas, especialmente os "sorbonistas" tinham grandes ressalvas às elites brasileiras e aos partidos políticos. Eles creditavam à incompetência das classes dirigentes em governar o país, ao crescimento dos movimentos populares e a falta de recursos técnicos e de capital disponível que permitisse ao país sair do subdesenvolvimento. É sobre esta tecla que a elite da ESG baterá durante todo o período de 50 até o golpe de 64 .

Esse ponto de vista da ESG entra em conflito com a ala das Forças Armadas nacionalistas, que assumira a supremacia com a emergência do período democratizante, considerando que os nacionalistas acreditavam no "papel moderador" do exército em relação ao poder do Estado para reforçar as instituições democráticas e legitimar a autoridade constituída, além do controle da “ordem" entre as classes sociais. Dessa maneira propiciando ao Estado, condições de intervir no desenvolvimento nacional sob a égide da união capital-trabalho, onde o desenvolvimento capitalista propiciaria a defesa e a consolidação dos interesses das classes trabalhadoras.

Para entender a doutrina de segurança nacional através da ESG, nada melhor do que um dos seus idealizadores: o general Cordeiro e Farias no seu discurso de despedida daquela instituição no começo de dezembro de 1952. O discurso foi publicado em três dias consecutivos pelo jornal Tribuna da Imprensa de propriedade do Sr. Carlos Lacerda e é detalhadamente analisado pelo articulista:

o discurso do general Cordeiro pode ser condensado em 10 pontos, sem prejuízo do seu desenvolvimento: 1-Segurança Nacional não abrange apenas as Forças Armadas. A interdependência das nações é hoje essencial à segurança. Dentro de cada nação, todo o seu potencial constitui alicerce da segurança. Este é um ponto que todos reconhecem, menos os que são contra ela. 2- Ela é sólida quando os 
cidadãos possuem: a. liberdade para viver e trabalhar; b. economia livre, limitada apenas quando se torna nociva ao interesse público; c. garantias individuais; $d$. governo e partidos a serviço da coletividade (e não o contrário); e. política exterior firme e decidida, mesmo com sacrifícios, tendo em vista o interesse permanente do Estado. (Por outras palavras: participação militar do Brasil na Coreia) ${ }^{22}$. 3- O estado de segurança de um país é a resultante de sua política nacional interna ou externa. Neste ponto convém acentuar que nos faltam, no Brasil, os itens (a), (b), (d) e (e). Quanto ao (b) funciona mais ou menos, com breves exceções. ${ }^{23}$

Observa-se uma verdadeira sintonia entre as posturas do general e a de Lacerda, ambos se esforçam para apontar a dicotomia entre a Segurança Nacional e sua plena realização na conjuntura que se estabelecia, na qual ficava clara a falência do poder público por não ter uma política de Estado. Esse fator, segundo eles, se agravava por não estarem, estes poderes civis, embasado em preceitos de desenvolvimento econômico e de segurança nacional que pudessem levar o país "à verdadeira democracia", onde os "interesses do Estado são os interesses de seus cidadãos". Nesse sentido, a sintonia entre os princípios da ideologia de Segurança Nacional e o Estado era condição primordial para o desenvolvimento da nação. Sem ela o Estado se tornava acéfalo, refém de interesses e grupos estranhos aos objetivos nacionais.

Lacerda se apropria do discurso e faz das palavras do general as suas, numa crítica contumaz àquela conjuntura de conflitos, além de revelar como a imprensa e alguns setores da UDN que ele representava, encaravam e endossavam a posição do referido general. Cordeiro e Farias começa apontando o principal problema nacional: "a minoria comunista controla grande parte das atividades nacionais",

Por sua "atividade, técnica, disciplina, coesão, seu poder de penetração e de exploração, de todos os fatos e circunstâncias, sua luta por alcançar lugares chave, apesar muitas vezes de seu pouco valor", agindo "de baixo para cima, deturpando, mentindo, examinando unilateralmente todos os problemas do país [...] dirigindo-se aos interesses materiais das diferentes camadas sociais, criando e fomentando a luta de classes, quando em lugares especiais, propícios, não dão origem a questões tendentes à desmoralização do regime e do governo. ${ }^{24}$

Esses exemplos mostram o "rolo compressor" que era o jornal Tribuna da Imprensa cujo principal editor alardeava o pensamento anticomunista e antigetulista extremado que tomava conta dos segmentos da burguesia naqueles idos anos. Quanto mais lemos as críticas de Carlos Lacerda, mais fica clara a aproximação desse órgão da imprensa a favor da ideologia militar "sorbonista", em detrimento dos nacionalistas e tudo que pudesse remeter ao governo de Getúlio Vargas. Trata-se, conforme ambos consideravam de um eminente estado de guerra ${ }^{25}$, e conforme as palavras do próprio General Cordeiro e Farias, sobre "a participação nas frentes do mundo" da luta durante a guerra fria:

a. Que a guerra geral já está desencadeada por meio de atos bélicos preparatórios.

b. Que não podemos nos furtar a essa evidência e temos de tirar dela as nossas 
conclusões. c. Que devemos participar da luta, se queremos participar das vantagens do mundo livre. d. Que assim obteremos recursos para desenvolver o país, libertando-nos da escravidão pela miséria. e. O outro sintoma da doença que afeta a segurança nacional, diz o general Cordeiro, é o conflito ideológico. ${ }^{26}$

A sintonia do discurso "nacional" com aquele da "Guerra Fria" é a dimensão da ideologia capitalista mais abrangente, onde os interesses do "capital" não dependem de nacionalidade, mas sim da harmonização dos interesses de classe com sua prática política. No caso da fala do general é presente que se esperava que o Estado brasileiro pudesse tirar proveito das benesses do "mundo livre”. Com tal lógica o discurso navega sobre as condições necessárias para o Brasil entrar na lista das nações capitalistas, mostrando os caminhos para o desenvolvimento econômico através de uma Política de Segurança Nacional, que neutralizasse o "inimigo interno" a qualquer custo, "sob pena de dias incrivelmente difíceis e talvez trágicos". ${ }^{27}$

Para o General Cordeiro e Farias a proliferação do comunismo no Brasil se manifestava não apenas no próprio comunismo que, naquelas alturas, ele considerava o menos grave, mas na cultura de conivência com este problema manifestado pelas elites. Além da ausência de uma verdadeira democracia que só poderia se viabilizar com as massas conscientes de seu papel. Apontando as distorções da democracia na incompetência das elites e suas instituições, "os partidos são pseudônimos do caudilhismo, do personalismo e da demagogia por covardia, e a escola se transforma nessas usinas de imbecilização coletiva que todos veem e às quais ninguém dá jeito."28

Esses aspectos reforçam a necessidade de "instrução" não só das massas trabalhadoras, mas também das elites, dos partidos políticos, para que toda sociedade civil recupere o "espírito cívico" e o comprometimento com as doutrinas do Estado. Essa concepção acredita que o Estado forte determina os caminhos para o desenvolvimento econômico e político da nação e consequentemente a "paz social" e o fim dos antagonismos de classe, na medida em que toda a sociedade estivesse engajada nos princípios de uma política de segurança nacional.

Se a fala do general Cordeiro e Farias na imprensa revela a lógica imediata da ESG, frente àquela conjuntura, o discurso do general Juarez Távora ${ }^{29}$, na solenidade de diplomação de estagiários da ESG em 1953, dá uma dimensão intelectualizada dos princípios da Escola, numa exposição esmiuçada dos problemas nacionais, dos seus desdobramentos que interferem no longo caminho do desenvolvimento econômico, político e social do país, e aponta alternativas para a sua resolução. A sofisticação do discurso revela o alto grau de conhecimento sobre a filosofia da ESG e a que se destina.

O discurso é composto de 21 páginas e fornece um panorama geral da conjuntura nacional e dos possíveis caminhos para aqueles diplomados de 1953, que a partir daquele momento seriam responsáveis pela disseminação e aplicação dos conhecimentos recebidos naquela instituição. O General começa sua fala definindo a ESG: 
O mais alto instituto de estudos referentes ao problema da Segurança Nacional, existente no país e a cujos cursos concorrem, em igualdade de condições, militares de terra, mar e ar, e civis oriundos de todos os segmentos de nossa elite social. ${ }^{30}$

O que visa o curso superior de guerra:

o fim último visado pela Escola Superior de Guerra é processar, por sedimentações sucessivas, uma Doutrina de Segurança Nacional, capaz de garantir, através da transitoriedade normal dos governos democráticos, a continuidade indispensável de pensamento e de ação, nesse setor fundamental de nossas responsabilidades públicas [...] objetiva preparar civis e militares de nossa elite, para a formulação e aplicação objetivas de uma Política de Segurança Nacional, que se impõe para a salvaguarda perene dos ideais, aspirações e interesses do povo brasileiro. ${ }^{31}$

Como se vê, o caráter tutelar das Forças Armadas frente à realidade nacional é o prisma fundamental dos princípios da instituição. $O$ general salienta que a Escola não tem por missão inculcar uma nova cultura aos seus alunos, mas complementar e adequar à cultura de que já são portadores. Visa, mediante um processo peculiar de nivelamento cultural, abranger "todos os aspectos de nossa vida nacional e de relações - os políticos (internos e externos), os econômicos, os psicossociais e os militares." 32 Nesse sentido define o general:

Considera-se hoje a segurança nacional como sendo "o grau relativo de garantia que, por meio de ações políticas, econômicas, psicossociais e militares, um Estado proporciona ao grupo humano que o integra, para a consecução e salvaguarda de seus objetivos nacionais. ${ }^{33}$

\section{O instrumento dessa garantia é o Poder Nacional,}

a expressão integrada dos meios de toda ordem de que a nação efetivamente dispõe, no momento considerado, para promover, a despeito de quaisquer antagonismos internos ou externos, a consecução e preservação dos objetivos nacionais. ${ }^{34}$

Concebe-se, assim, o Estado como uma entidade que se coloca acima dos antagonismos de classe para promover a união dos objetivos nacionais garantindo que a elite nacional estabeleça os rumos do desenvolvimento e o bem comum. Tal Política de Segurança Nacional é, portanto, sinônima de estratégia geral garantidora da hegemonia da própria política nacional. ${ }^{35}$

Assim os estudos da Escola são orientados no sentido de habilitar os estagiários do curso para a formulação de um conceito estratégico nacional, isto é,

à determinação dos objetivos nacionais, cujo alcance e salvaguarda podemos e devemos assegurar imediatamente, e à definição das linhas políticas mais adequadas para alcançar e manter tais objetivos; e, em seguida, à dedução das diretrizes para o planejamento da Segurança Nacional, e à pratica de tal planejamento. $^{36}$ 
Munidos desse conceito de Política de Segurança Nacional o Curso de Estado-Maior e Comando das Forças Armadas tinha o objetivo de habilitar os oficiais das três armas para o exercício das funções de comando e de chefia para o desenvolvimento de uma doutrina brasileira de comando.

O general Távora propõe ainda algumas medidas que contribuiriam para a resolução dos problemas nacionais. Em primeiro lugar, diz ele, deveria ser implantada uma burocracia estatal para o controle, planejamento e responsabilidade funcional, através da redução dos grandes órgãos ligados aos altos escalões, propiciando, assim, uma coordenação efetiva político, econômicofinanceira, bem-estar-social e a defesa nacional, em outras palavras à centralização dos "negócios do Estado":

A criação de órgãos permanentes e especializados de planejamento, coordenação e controle administrativos, na presidência da república e nos grandes órgãos a ela diretamente subordinados, para que possam os mais elevados agentes da administração delinear, coerentemente, num quadro de conjunto, os objetivos globais de sua ação. ${ }^{37}$

Em segundo, deveria existir uma segurança coletiva no campo internacional, através da cooperação dos organismos internacionais como a ONU e OEA, pelos quais houvesse o comprometimento de ajuda mútua, em relação ao continente americano. Em terceiro, seria necessário adotar uma enérgica política de discriminação dos financiamentos controláveis pelo poder público, dentro de um critério razoável de importância e urgência dos empreendimentos a expandir, evitando o descompasso no ritmo do desenvolvimento nacional. Em quarto, era imprescindível adotar uma política de preservação do solo, da fauna e das florestas, garantindo a recuperação e a conservação desse "imenso e inestimável patrimônio que nos legaram os nossos antepassados". 38 Considerava ainda necessário estabelecer uma política educacional focada no desenvolvimento da força de trabalho qualificada em detrimento do ensino com excessiva preocupação teórica.

O aspecto mais discutível do sistema educacional brasileiro é a sua pouca objetividade. Num país com índice de analfabetismo ainda superior a $50 \%$ e onde apenas $6 \mathrm{em}$ cada 10.000 habitantes conseguem ingressar na universidade, o sistema educacional parece estar paradoxalmente orientado no sentido de conduzir todos os educados aos bancos universitários.[...] Não seria mais útil e adequado às condições gerais de nossa vida, se, pelo menos nos estabelecimentos oficiais, fosse ele orientado dentro de uma finalidade profissional, qual a dos cursos destinados à formação de técnicos de grau médio, facultando-se aos seus diplomados, se o quisessem, o ingresso, posterior, na universidade ? $^{39}$

Naquela conjuntura de desenvolvimento industrial e econômico, onde se manifestava carência de mão-de-obra qualificada, considerava o general que o sistema educacional poderia incrementar tal demanda, mas esse discurso revela também, "que uns nascem para trabalhar e outros para 
pensar”, pois apesar de tal realidade, que afasta a maioria da população do ensino educacional, o general não sugeriu que houvesse maior investimento do Estado no aperfeiçoamento das escolas e na absorção dessa população para que tivessem acesso a um ensino superior e de qualidade.

A saída proposta por ele reforça a descriminação do trabalho manual versus o intelectual, na medida em que o pensamento militar desenvolvido acredita que a elite é responsável pelo planejamento e supervisão das políticas incrementadas pelo Estado, enquanto que o "povo" é o que as executa através do seu trabalho.

O general aponta outro aspecto da realidade educacional que, segundo ele, seria deveras importante: o moral, "Que deve ser aprimorado pela elevação dos sentimentos e pela formação do caráter, aí incluída a disciplina da vontade" ${ }^{\natural 0}$. Deduz-se que a falta de moral e de caráter é que coloca esse indivíduo como contestador no universo fabril ou rural no seu ingresso no mundo do trabalho.

Finalmente, como última propositura, defendia a instituição de uma legislação social que garantisse maior amparo aos assalariados rurais, e também se deveria estimular um amplo diploma de reforma agrária para evitar a migração do campo para a cidade.

Em relação à remuneração e aos direitos e deveres do trabalhador naquela conjuntura inflacionária e de arrocho salarial, a proposta do general era inovadora, propondo o valor do salário conforme o desempenho ${ }^{41}$, ou seja, o salário produtividade tão em voga nos dias atuais.

Na descrição dessa medida a fala do general diz tudo:

Parece, assim, urgente, que firmemos um rumo e atuemos, com decisão no sentido de preparar a elite e o povo brasileiro para a desobriga de seus compromissos internacionais; de trabalhar com eficiência, dentro da liberdade democrática; e de acolher inteligentemente a colaboração alienígena que nos ajude no esforço de forjar, quanto antes, o verdadeiro e melhor escudo contra a infiltração comunista a elevação razoável, em tempo útil, do padrão de vida do nosso povo. ${ }^{42}$

Em relação a essa questão o general acusa a propaganda sorrateira, desleal e sistemática de instigar e desunir as nações democráticas do bloco ocidental, a incompatibilizar, em cada uma delas, a massa com a elite, e a entravar,

através de engodos dialéticos, o processo de seu desenvolvimento econômicosocial, a fim de manter em boas condições o caldo de cultura, de atraso e de miséria, de que necessita para o fermento de cizânia e de ódio, com que anda a envenenar o espírito das massas e da própria elite. ${ }^{43}$

O general critica a reação a essa propaganda, que oscila,

inexplicavelmente entre o emprego esporádico da violência, contra adeptos e simpatizantes do comunismo, e uma complacência sem limites, que tem chegado, em alguns casos, à adesão, inconsiderada, por vezes, de importantes setores de 
nossa elite às campanhas, através dos quais ministram os comunistas o veneno de seus ódios e intrigas. ${ }^{44}$

O centro desse pensamento é que o desenvolvimento econômico, através do capital internacional, possibilitaria a superação das mazelas sociais, propiciando melhor condição de vida para o povo brasileiro. E o empecilho para essa realização, era a infiltração comunista veiculada através dos discursos nacionalistas de vários grupos sociais como já foi demonstrado nos parágrafos anteriores.

Além de todas estas propostas, considerava ainda que seria necessário investir na melhoria da infraestrutura nas Forças Armadas através da unidade de supervisão administrativa das três armas, no preparo sistemático dos quadros dessas forças para o planejamento e comando de operações combinadas e por último o reaparelhamento material equilibrado das forças de terra, mar e ar.

Percebe-se a proposta de institucionalização da ESG nos aparelhos burocráticos do Estado, em todos os níveis da administração pública e militar, garantindo que o binômio Desenvolvimento e Segurança fossem garantidos em todas as instâncias. Por isso o general enaltece a Associação dos Diplomados da Escola Superior de Guerra (ADESG) que tinha como missão, projetar, ampla e decididamente, no seio de nossa elite, as ideias e métodos de trabalho definidos pela ESG.

Finalizando o seu discurso para os futuros "ideólogos do sistema", o general afirma que esse conjunto de medidas seria um meio de resolução dos problemas nacionais, atacando-os de frente sem subterfúgios, "sob pena de desacreditar-nos, como elite, perante o povo por cujos destinos somos responsáveis, e perante o mundo exterior, contra tais ambições e concorrências, devemos defendê-lo". ${ }^{45}$

Se os generais Cordeiro e Farias e Juarez Távora eram os fiéis representantes da ESG, destrinchando nesses discursos as suas visões de Estado e os seus diagnósticos sobre os problemas nacionais, outro famoso general, em palestra no Rio Grande do Sul em dezembro de 1954, Estilac Leal, mostrou a sua interpretação a respeito. Apesar de estar na outra ponta do embate nas Forças Armadas (como nacionalista), demonstra como, de fato, o limiar entre os nacionalistas e "sorbonistas" era "apenas um ponto de vista". Segundo ele, seria um conflito entre facções para consolidar seu espaço político junto ao governo e nas Forças Armadas, mas não antagônico como os "sorbonistas" queriam tanto demonstrar para a sociedade civil:

O General Estilac Leal, palestrando nessa capital, num dos últimos dias deste mês, numa roda que discutia problemas relacionados com o panorama nacional, afirmou categoricamente, após haver sido considerado, por um dos presentes, como um elemento possuidor de ideias muito avançadas: 'Eu já sei onde quer o senhor chegar: O senhor, como outros, pensa que eu seja um comunista. Enganam-se todos. Eu sou daqueles que querem ver tantos os fascistas como os comunistas esmagados de baixo dos pés. Nenhum deles presta. A verdadeira democracia é aquela que se alicerça nos princípios básicos da maçonaria, que cultivam a solidariedade humana, o respeito do forte pelo fraco. Esta é a minha doutrina. Fora 
dela tudo irá por água abaixo. Aliás, inevitável degringolada é que esta reservada a Getúlio e seus acompanhantes, se continuarem com a demagogia barata a que estão entregues. ${ }^{46}$

Os militares sabiam que um apoio direto do PCB às suas plataformas nacionalistas, juntamente com a mobilização das classes trabalhadoras, seria em médio prazo fator preponderante para tentativas de golpe, naqueles tempos de pressão "ideológica", quando não havia possibilidade da neutralidade política: ou se era comunista ou não era. O General Estilac já advertira o presidente Vargas do perigo de ter "Jango" nas suas fileiras, pois certamente, "mais tarde muitos aborrecimentos terá". ${ }^{47}$

Muito mais duro do que os discursos dos Generais Cordeiro e Farias e Juarez Távora, o general Estilac Leal, acusado sempre de ser um militar comunista, surpreende com a sua proposta de "medidas drásticas":

Sou da opinião que só a adoção de medidas drásticas, inclusive o fuzilamento de uma meia dúzia de maus brasileiros, terá o condão de resolver a crise que atualmente afeta a ordem política e social do Brasil.[...] Foi por expor esse ponto de vista a até mesmo aconselhar a Getúlio a fazer a revolução antes que o povo a faça sob a orientação dos comunistas, é que me vi obrigado a pedir demissão, pois julguei haver recebido o "bilhete azul", quando Getúlio me disse, depois de ouvir atentamente as minhas palavras: "tu és muito precipitado e tens instinto muito sanguinário. ${ }^{48}$

O General Estilac Leal também vislumbrava tempos sombrios para um futuro não muito distante, pois assim como os "sorbonistas", acreditava na incapacidade do poder civil para resolver os problemas nacionais:

A realidade, porém, é esta; estamos atravessando uma época muito perigosa, hoje em dia, os que estão bem não se lembram dos que estão mal e os políticos que desfrutam das regalias outorgadas pelo povo, não tomam conhecimento da existência deste. $\mathrm{O}$ nosso grande presidente, por ser um homem bem intencionado, é que se debate sozinho diante da gravidade do momento, ludibriado a cada instante pelos aproveitadores e atacado desordenadamente pelos mal intencionados. $^{49}$

Finaliza preconizando que os responsáveis pela ordem pública, as polícias de ordem política e social, é que sofreriam as consequências desses erros provocados pelas autoridades constituídas, pois teriam que, praticamente sozinhos, aplicar com rigor a repressão para salvaguardar a pátria de seus inimigos:

os bons soldados de todos os setores responsáveis pela ordem pública é que sofrerão as consequências desses erros. Caber-lhes-a a missão mais ingrata, embora gloriosa: deverão enfrentar e derrotar os inimigos da Pátria, assegurando a esta o seu destino de nação livre e independente. ${ }^{50}$ 
Nessa perspectiva o final da Guerra Fria somente intensificou essa prática inerente ao capitalismo brasileiro, na medida em que o crescimento das agremiações de esquerda e a mobilização da classe trabalhadora representavam um perigo iminente para os interesses da burguesia engendrada nos interesses do capital mundializado. Assim, o estabelecimento da ESG naquele período e o debate sobre os riscos da democracia que aí se configura caracterizam a ação das Forças Armadas em prol a manutenção do "status quo" 51 , seja defendendo um desenvolvimento com maior ou menor participação do capital internacional. É neste contexto que se gesta o ideário sobre a segurança nacional que, posteriormente, engendra a Doutrina de Segurança Nacional. Neste sentido, retomando Francisco Ferraz:

Esta confluência de aspirações entre elites militares e civis pôde fazer da recém implantada Escola Superior de Guerra um espaço privilegiado para a moldagem de um projeto político comum. Estavam assim cada vez mais distantes as reservas existentes entre os membros das Forças Armadas e algumas frações burguesas em ascensão, o que acabaria permitindo um relacionamento mais equilibrado. A doutrina da Segurança Nacional, ideologia aglutinadora desses interesses, contribuía para a ação política de classe, gestando estrategicamente um planejamento com fins específicos, voltado para a construção de uma sociedade industrial plenamente articulada ao capitalismo mundial. (FERRAZ, 1994, p.44).

O resultado é que os militares têm desempenhado um papel decisivo na política brasileira, considerando que os grupos dominantes os cooptam em épocas de conflito político, e os golpes concretos contra o executivo representam os esforços combinados entre civis e militares. O pêndulo da balança garante assim, ao segmento da burguesia atrelado ao capital internacional, o domínio da condução política que se coadune com seus interesses econômicos, apesar de sua fragilidade e pouca base social.

\section{Referências Bibliográficas}

ALMEIDA, Lúcio Flávio de. Uma ilusão de desenvolvimento - Nacionalismo e Dominação Burguesa nos anos JK. Florianópolis: UFSC, 2006.

ALVES, Maria Helena Moreira. Estado e Oposição no Brasil (1964-1984). Bauru,SP: Edusc, 2005.

ANDRADE JÚNIOR, Hermes. Matrizes ideológicas presentes no segmento militar brasileiro: o caso do Clube Militar (1950-1964). Revista Eletrônica de Ciências Sociais, Rio de Janeiro, Ano I, $\mathrm{n}^{\mathrm{o}} 1$, julho/dezembro de 2001.

ASSUNÇÃO, Vânia Noeli Ferreira de. O Satânico Doutor Go: A Ideologia Bonapartista de Golbery do Couto e Silva. São Paulo: PUCSP, 1999.

CARVALHO, José Murilo de. Forças Armadas e política no Brasil. Rio de Janeiro: Zahar, 2005. 
CHASIN, J. A miséria brasileira: 1964-1994: do golpe militar à crise social. Santo André: Ad Hominem, 2000.

COTRIM, Lívia. O capital atrófico: da via colonial à mundialização. In: CHASIN, J. A miséria brasileira: 1964-1994: do golpe militar à crise social. Santo André: Ad Hominem, 2000. . O ideário de Getúlio Vargas no Estado Novo. Dissertação de Mestrado. Campinas: UNICAMP, 1999.

DREIFUSS, René Armand. 1964, A conquista do Estado: ação política, poder e golpe de classe. Petrópolis,RJ: Vozes, 2006.

FERRAZ, Francisco César Alves. À sombra dos carvalhos: militares e civis na formação e consolidação da Escola Superior de Guerra. Dissertação de Mestrado. Assis, SP: Universidade Estadual Paulista, 1994.

RAGO FILHO, Antonio. O ardil do politicismo: do bonapartismo à institucionalização da autocracia burguesa. Revista Projeto História (29), tomo 1, São Paulo: Educ, dezembro de 2004, pp. 139-167.

REZNIK, Luís. Democracia e Segurança Nacional: A polícia política nos pós Segunda Guerra Mundial. Tese de Doutorado. Rio de Janeiro: Instituto Universitário de Pesquisas, 2000.

ROCHA, Maria Selma de Moraes. A evolução dos conceitos da doutrina da Escola Superior de Guerra nos anos 70. São Paulo: USP,1996.

SILVA, Hélio. 1945: Por que depuseram Vargas. Rio de Janeiro: Civilização Brasileira, 1976.

TERÁN, Oscar (coord). Ideas em el siglo, intelectuais ey cultura em el siglo XX latino-americano. Buenos Aires: Siglo XXI, 2004.

\section{NOTAS}

${ }^{1}$ Este artigo é parte modificada de minha dissertação de mestrado intitulada A vigilância do DOPS-SP às Forças Armadas (Brasil década de 50) sistema repressivo num Estado de natureza autocrática. Pontifícia Universidade Católica de São Paulo, 2008, que contou com apoio da CAPES. Orientadora Prof. Dr ${ }^{a}$. no Departamento de História da PUC-SP. Coordenadora do Centro de Estudos de História da América Latina (CEHAL). E-mail: vevivevi.vieira@gmail.com

${ }^{2}$ Esse posicionamento é o embrião da ideologia que norteará a Escola Superior de Guerra após a sua fundação.

${ }^{3}$ Conforme Rago "a forma da dominação autocrático-burguesa constitui-se num domínio exercido de modo indireto pelo conjunto da burguesia, pelas armas, subjugando, castrando ou atrelando os poderes legislativo e judiciário" (Rago, 1998, p.15)

${ }^{4}$ Conforme defende Selma Rocha em seu estudo sobre esta instituição, observa-se diferenças e divergências entre os oficiais brasileiros e os integrantes da missão militar norte-americana no que se refere ao papel da nova instituição, já que oficialato brasileiro considerava necessário preparar o conjunto da elite brasileira, militar e civil, para dirigir o Estado nessa nova conjuntura internacional.

${ }^{5}$ A participação da FEB, dentro do $5^{\circ}$ Exército, naturalmente ensejou a aceitação das normas adotadas pelo National War College. A Força Expedicionária Brasileira, o grupo da Força Aérea e o emprego da nossa Marinha na defesa do Atlântico Sul haviam aproximado brasileiros e americanos no trato da guerra e na aprendizagem de suas lições.

${ }^{6} \mathrm{O}$ General Antonio Jorge Correia foi comandado do General Médici por várias vezes e, inclusive, foi o seu subcomandante na Academia Militar de Agulhas Negras (AMAN), em 31 de março de 1964.

${ }^{7}$ A segurança nacional: sua conceituação seu estudo na ESG. Rio de janeiro, ESG, documento C-01-59, pp.4-5 Apud FERRAZ, 1994:39.

${ }^{8}$ Revista da Escola Superior de Guerra v.3 ,nº, pp.9-15 Apud FERRAZ,1994, p. 26.

${ }^{9}$ Neste sentido, observa Chasin que a autocracia burguesa institucionalizada é a forma de dominação burguesa em 
'tempos de paz', e o bonapartismo é a forma da dominação burguesa em 'tempos de guerra'.

${ }^{10} \mathrm{Na}$ verdade, as ideias que permeiam a Doutrina de Segurança Nacional, no Brasil, se constituíram na adaptação de ideias desenvolvidas no exterior para a realidade brasileira. Pode-se dizer que, no processo social e político iniciado a partir de 1930, já estavam sendo cultivadas algumas das sementes para as ideias desenvolvidas na Escola Superior de Guerra.

${ }^{11}$ Ver: CASANOVA, Pablo González (org.). América Latina: história de meio século. Brasília: Ed. Universidade de Brasília, 2 vols. 1988. SADER, Eder. A militarização do Estado na América Latina. São Paulo: Ed. Polis, 1982.

${ }^{12}$ Segundo os positivistas, cabia ao Estado, por meio da administração científica, racional, de seus lideres, zelar pela ordem, proteger os cidadãos e garantir os seus direitos, de uma forma quase tutelar. A ideia de um governo forte, inteiramente centralizado, uma verdadeira "ditadura republicana", portanto, sustentava o ideário positivista.

${ }^{13}$ A Cepal, criada em 1948 sob os auspícios das Nações Unidas, tinha o propósito de analisar os problemas de desenvolvimento latino - americano e propor políticas públicas para enfrentá-los.

${ }^{14}$ Após 1964, conforme apontam os autores, os "sorbonistas" se assumem a defesa da transitoriedade das Forças Armadas na condução do Estado, em oposição aos duristas que consideravam imprescindível que os militares continuassem no poder. Neste sentido ver FICO, Carlos. Como Eles Agiam. Rio de Janeiro: Record, 2000 e RAGO, Antonio Filho, tese de doutoramento. São Paulo, PUC:1998.

${ }^{15}$ Para elucidar esse aspecto da criminalização social ver artigo VIEIRA, V. L. A criminalização das Lutas Sociais na América Latina. Revista Projeto História - Revista do Programa de Pós-graduação em História da PUC/SP, v.31, 2005.

${ }^{16}$ Recorte de jornal não identificado datado de 31/03/1953. Relatório Reservado" Dossiê DEOPS 50.Z.09 documento n ${ }^{\circ}$ $201 \mathrm{~b}$

${ }^{17}$ A criação do Clube Militar ocorre dois anos antes de proclamação da República tendo como primeiro diretor presidente o Marechal Deodoro da Fonseca.

18 "Relatório Reservado" Dossiê DEOPS 50.Z.09 documento n 172 página 4, de 22.05.1952

${ }^{19}$ Idem

${ }^{20} \mathrm{Idem}$

${ }^{21}$ Relatório n 55 de 28/04/1954. "S.V.I." "SS" "Relatório Reservado". Dossiê DEOPS 50.Z.09 documento n 240

${ }^{22}$ A insistência dessa ala das Forças Armadas em participar da Guerra da Coreia estava inserida, na luta entre o capitalismo e o comunismo, entre o ocidente e o oriente, e o bloco ocidental representa o escudo contra a infiltração comunista no continente.

${ }^{23}$ Recorte do Jornal "Tribuna da Imprensa" datado de 08/12/1952 anexo ao "Relatório Reservado" Dossiê DEOPS 50.Z.09 documento $\mathrm{n}^{\mathrm{o}} 197^{\mathrm{a}}$

${ }^{24}$ Recorte do Jornal "Tribuna da Imprensa" datado de 08/12/1952 anexo ao "Relatório Reservado" Dossiê DEOPS 50.Z.09 documento $\mathrm{n}^{\circ}$ 197A

${ }^{25}$ Ver artigo: OLIVEIRA, N. D de. A animosidade dentro das Forças Armadas: vigilância e expurgo na caserna. Revista Tempo e Argumento. Florianópolis, v. 1, n. 2, p. 162 - 185, jul./dez. 2009.

${ }^{26}$ Recorte do Jornal "Tribuna da Imprensa" datado de 09/12/1952 anexo ao "Relatório Reservado" Dossiê DEOPS 50.Z.09 documento $\mathrm{n}^{\circ}$ 197B

${ }^{27}$ Recorte do Jornal "Tribuna da Imprensa" datado de 10/12/1952 anexo ao "Relatório Reservado" Dossiê DEOPS 50.Z.09 documento $\mathrm{n}^{\circ} 197 \mathrm{C}$

${ }^{28}$ Idem

${ }^{29}$ Em setembro de 1952, o general Juarez Távora assumiu a direção da Escola, e se consagrou como um dos grandes teóricos do pensamento militar.

${ }^{30}$ JT dpf 1952.09.06 Arquivo pessoal do general Juarez Távora, acervo documental da FGV-CPDOC

${ }^{31}$ Idem

${ }^{32}$ Idem

${ }^{33}$ Idem

${ }^{34}$ Idem

${ }^{35}$ Segundo Francisco Ferraz, A conceituação dos "Objetivos Nacionais" exigiu o desenvolvimento da ideia de interesses e aspirações nacionais, obviamente definidas pelas mesmas frações da burguesia brasileira que necessitavam conquistar uma posição hegemônica em meio às outras e perante a toda a sociedade. (FERRAZ, 1994, p.39)

${ }^{36}$ JT dpf 1952.09.06 Arquivo pessoal do general Juarez Távora, acervo documental da FGV-CPDOC

${ }^{37}$ Idem

${ }^{38}$ Idem

${ }^{39}$ Idem

${ }^{40} \mathrm{Idem}$

${ }^{41}$ Idem

${ }^{42}$ Idem

${ }^{43}$ JT dpf 1952.09.06 Arquivo pessoal do general Juarez Távora, acervo documental da FGV-CPDOC

${ }^{44}$ Idem

${ }^{45}$ Idem

${ }^{46}$ Tópico do relatório do Estado do Rio Grande do Sul - Boletim no 2 de 31/01/1954 "Relatório Reservado" Dossiê DEOPS 50.Z.09 documento ${ }^{\circ} 234$ 
47 Idem

48 Idem

49 Tópico do relatório do Estado do Rio Grande do Sul - Boletim no 2 de 31/01/1954 "Relatório Reservado" Dossiê DEOPS 50.Z.09 documento $n^{\circ} 234$

${ }^{50}$ Idem

${ }^{51}$ Além das conhecidas manifestações de golpe e contragolpe ao governo JK como o contragolpe de novembro de 1955 liderado pelo General Lott, o levante de Jacareacanga em fevereiro de 1956 e Aragarças em dezembro de 1959 que revelavam um "racha" no interior das Forças Armadas, havia outros grupos simpatizantes as ideias "esguianas" que propunham a derrubada do governo e uma reorientação na condução do Estado, o Movimento de Recuperação Nacional (1956), Frente Militar Revolucionária (1956) e o conhecido Movimento Militar Constitucionalista (1955) que apesar de defender a legalidade constitucional também elaboram um programa de golpe militar a favor da constitucionalidade. Ver artigo: OLIVEIRA, N. D. de. As Forças Armadas na mira do Serviço Secreto do DOPS-SP : golpe e contragolpe (1955-1956). Dossiê "História e Defesa". Coordenado pelo Prof. Dr. Celso Castro, diretor do CPDOC da Fundação Getúlio Vargas. Correspondente ao v. 2, n. 4, jul.-dez. de 2009.

Artigo recebido em 09/2010. Aprovado em 11/2010. 